\title{
Efficacy and Safety of Medication for Attention-Deficit Hyperactivity Disorder in Children and Adolescents with Common Comorbidities: A Systematic Review
}

\author{
Noa Tsujii (D) - Masahide Usami · Noriyuki Naya (D) - Toshinaga Tsuji (D) • \\ Hirokazu Mishima · Junko Horie · Masakazu Fujiwara • \\ Junzo Iida
}

Received: February 9, 2021 / Accepted: April 9, 2021 / Published online: June 4, 2021

(C) The Author(s) 2021

\section{ABSTRACT}

Introduction: Comorbid psychiatric conditions in children and adolescents with attention-deficit hyperactivity disorder (ADHD) occur frequently, complicate management, and are associated with substantial burden on patients and caregivers. Very few systematic reviews have assessed the efficacy and safety of

Noa Tsujii and Masahide Usami contributed equally to the manuscript and are co-first authors.

Supplementary Information The online version contains supplementary material available at https:// doi.org/10.1007/s40120-021-00249-0.

N. Tsujii $(\bowtie)$

Department of Neuropsychiatry, Faculty of Medicine, Kindai University, Osakasayama, Osaka, Japan

e-mail: tujiinoa@med.kindai.ac.jp

M. Usami

Kohnodai Hospital, National Center for Global

Health and Medicine, Chiba, Japan

N. Naya $\cdot$ T. Tsuji $\cdot$ H. Mishima $\cdot$ J. Horie

Medical Affairs Department, Shionogi \& Co., Ltd.,

Osaka, Japan

M. Fujiwara

Data Science Office, Shionogi \& Co., Ltd., Osaka, Japan

J. Iida

Faculty of Nursing, Nara Medical University,

Kashihara, Nara, Japan medications for ADHD in children and adolescents with comorbidities. Of those that were conducted, most focused on a particular comorbidity or medication. In this systematic literature review, we summarize the efficacy and safety of treatments for children and adolescents with ADHD and comorbid autism spectrum disorders, oppositional defiant disorder, Tourette's disorder and other tic disorders, generalized anxiety disorder, and major depressive disorder.

Methods: We searched MEDLINE, Embase, and ClinicalTrials.gov (to October 2019) for studies of patients (aged < 18 years) with an ADHD diagnosis and the specified comorbidities treated with amphetamines, methylphenidate and derivatives, atomoxetine (ATX), and guanfacine extended-release (GXR). For efficacy, placebocontrolled randomized controlled trials (RCTs) or meta-analyses of RCTs were eligible for inclusion; for safety, all study types were eligible. The primary efficacy outcome measure was ADHD Rating Scale IV (ADHD-RS-IV) total score.

Results: Of 2177 publications/trials retrieved, 69 were included in this systematic literature review (5 meta-analyses, 37 placebo-controlled RCTs, 16 cohort studies, 11 case reports). A systematic narrative synthesis is provided because insufficient data were retrieved to combine ADHD-RS-IV total scores or effect sizes. Effect sizes for ADHD-RS-IV total scores were available for ten RCTs and ranged from 0.46 to 
1.0 for ATX and from 0.92 to 2.0 for GXR across comorbidities. The numbers and types of adverse events in children with comorbidities were consistent with those in children without comorbidities, but treatment should be individualized to ensure children can tolerate the lowest effective dose.

Conclusion: Limited information is available from placebo-controlled RCTs on the efficacy (by ADHD-RS-IV) or safety of medication in children with ADHD and psychiatric comorbidities. Further studies are required to support evidence-based drug selection for these populations.

Keywords: Adolescent; Attention deficit hyperactivity disorder; Child; Comorbidity; Pharmacotherapies

\section{Key Summary Points}

\section{Why carry out this study?}

Comorbid psychiatric conditions in children and adolescents with attentiondeficit hyperactivity disorder (ADHD) occur frequently, complicate management, and are associated with substantial burden on patients and caregivers.

This systematic literature review summarizes the efficacy and safety of amphetamines, methylphenidate and derivatives, atomoxetine (ATX), and guanfacine extended-release (GXR) for children and adolescents with ADHD and comorbid autism spectrum disorders, oppositional defiant disorder, Tourette's disorder and other tic disorders, generalized anxiety disorder, and major depressive disorder.

\section{What was learned from the study?}

Effect sizes for ADHD Rating Scale IV total scores were available for ten randomized placebo-controlled trials and ranged from 0.46 to 1.0 for ATX and 0.92 to 2.0 for GXR across comorbidities.
Although the numbers and types of adverse events in children with comorbidities were consistent with those in children without comorbidities, treatment should be individualized to ensure that children can tolerate the lowest effective dose.

Further studies are required to support evidence-based drug selection for children with ADHD and psychiatric comorbidities.

\section{DIGITAL FEATURES}

This article is published with digital features, including a summary slide, to facilitate understanding of the article. To view digital features for this article go to https://doi.org/10.6084/ m9.figshare.14387378.

\section{INTRODUCTION}

Comorbid psychiatric conditions in children and adolescents with attention-deficit hyperactivity disorder (ADHD) are highly prevalent, complicate management and treatment $[1,2]$ and contribute to substantial burden on patients and caregivers $[3,4]$. More than half of all children and adolescents diagnosed with ADHD have one or more psychiatric comorbidity, and more than one-quarter have two or more comorbidities [1]. Common comorbidities in children with ADHD include, but are not limited to, conduct disorders, particularly oppositional defiant disorder (ODD), Tourette's disorder and other tic disorders, generalized anxiety disorders, and major depressive disorder (MDD) [5]. Less is known about the prevalence of comorbid autism spectrum disorder, partly because of the evolution of the definition and diagnostic criteria for this condition [5].

In general, first-line treatment of children and adolescents with ADHD should include parent-based behavior management training and classroom-based behavioral training in combination with or before the administration 
of pharmacological treatment [6]. Pharmacological treatments decrease ADHD symptom (i.e., inattention, hyperactivity, and impulsivity) severity and, combined with behavior training, contribute to improvements in functional outcomes, such as self-esteem, independence, social relationships, and educational status [7]. The pharmacological treatments currently recommended for use in adolescents and children include fast-acting psychostimulants (i.e., amphetamines, methylphenidate) and non-stimulants (i.e., atomoxetine [ATX], alpha2 agonists) [6]. In contrast to the 2014 Japanese clinical guidelines, which recommend both stimulants and non-stimulants as first-line pharmacological treatment for children and adolescents ( $\geq 6$ years) with ADHD [8], European and North American guidelines recommend stimulants as first-line pharmacological treatment, followed by non-stimulants, such as ATX or guanfacine extended-release (GXR), for those who do not respond to or cannot tolerate stimulants [7, 9-11]. In all settings, however, the presence of comorbidities adds complexity to the management of children and adolescents with ADHD $[7,8]$, and certain medications may be preferred or contraindicated depending on the comorbidities that are present.

Multiple systematic reviews and meta-analyses have assessed the efficacy and safety of medications for ADHD in children and adolescents [12-15]. Of the few systematic reviews and meta-analyses conducted in children and adolescents with comorbidities, most have focused on a particular comorbidity or medication [16-23]. The objectives of this systematic literature review are to summarize the efficacy and safety of medications, including amphetamine and its derivatives (AMPs), methylphenidate and its derivatives (MPHs), ATX, and GXR for treatment of children and adolescents with ADHD and the following common psychiatric comorbidities: autism spectrum disorders, ODD, Tourette's disorder and other tic disorders, generalized anxiety disorder, and MDD.

\section{METHODS}

A literature search protocol was developed for this study in accordance with the Preferred Reporting Items for Systematic Reviews and Meta-Analyses (PRISMA). This article is based on previously conducted studies and does not contain any new studies with human participants or animals performed by any of the authors.

\section{Data Sources and Search Terms}

In accordance with the protocol, we searched MEDLINE (1946 to October 2, 2019) and Embase (1974 to October 2, 2019) via Ovid. Searches were adapted for each database and included keywords (Medical Subject Heading or EMTREE) and free-text terms for ADHD, comorbidities (autism spectrum disorders, ODD, Tourette's disorder and other tic disorders, generalized anxiety disorder, MDD), and medications (AMPs, MPHs, ATX, GXR). Clonidine was not included because at that time it was not a universally approved medication for ADHD in children and adolescents. ClinicalTrials.gov was searched on October 29, 2019 (completed studies with results that included patients aged $\geq 6$ years and $<18$ years with ADHD). Searches were limited to studies in humans, with no restrictions on publication dates or language. The complete search strategies used for MEDLINE and Embase are available in the Electronic Supplementary Material (ESM): Electronic search strategies.

\section{Eligibility Criteria}

The inclusion criteria were as follows: studies of patients (aged $\geq 6$ years and $<18$ years) with a diagnosis of ADHD and any one or more of the specified comorbidities (autism spectrum disorders, ODD, Tourette's disorder and other tic disorders, generalized anxiety disorder, and MDD); single-arm or comparative studies including oral administration (any dose) of AMPs, MPHs, ATX, or GXR in $\geq 1$ treatment arm and a treatment duration $\geq 7$ days (to avoid single-dose studies or studies with limited 
treatment durations); and studies reporting the clinical efficacy and/or safety of medications for ADHD symptoms.

For efficacy outcomes, only placebo-controlled randomized controlled trials (RCTs) or meta-analyses of RCTs of patients on active treatment were eligible. For safety outcomes, patients on active or maintenance treatment were included; all study types were eligible.

The main exclusion criteria were as follows: studies of adult (aged $\geq 18$ years) patients with ADHD or patients diagnosed with ADHD using the Diagnostic and Statistical Manual of Mental Disorders (DSM), 2nd Edition; studies that included child and adolescent patients with ADHD only, did not state whether patients with comorbidities were included or excluded, and did not report results separately for patients with ADHD and comorbidities; studies of other drugs, such as anticonvulsants or atypical antipsychotics, other routes of administration, or single oral administration of treatments; or studies of patients with epilepsy or congenital risk factors (e.g., heart disease) or who were pregnant. Duplicate publications or publications reporting duplicate data, conference proceedings or abstracts, review articles, commentaries, and guidelines and consensus statements were not eligible.

Reference lists from relevant systematic reviews and meta-analyses were screened manually to identify any additional eligible studies.

\section{Screening and Data Extraction}

Searches were collated using bibliographic management software. An initial screen of the title and abstract of each publication was conducted by one individual (non-author) to remove duplicate publications and identify potential publications for inclusion. Inclusion was confirmed after a review of the full text of all potential publications by a second individual (non-author). For instances where inclusion was uncertain, the decision to include or exclude was resolved by consensus between the two individuals, and the authors reviewed and approved the articles identified for inclusion in the review. One individual extracted all data into prespecified data tables and a second individual checked all extracted data; disagreements were resolved by consensus. Data were extracted into prespecified tables and included the study design, ADHD diagnosis criteria, percentage of patients with each comorbidity (as described in each publication), the primary efficacy outcome for each study, ADHD treatments administered (type, dose, duration), discontinuation rates, the number, age, and sex of patients enrolled in each treatment arm, and the efficacy and safety outcomes as described below.

\section{Outcomes}

Comorbidities are reported as described in each publication. The primary efficacy outcome measure was the ADHD Rating Scale IV (ADHDRS-IV) total score (investigator and/or parentrated), which is a validated measure of changes in ADHD symptom severity in response to treatment [24] and for which a minimal clinically important difference has been defined [25]. Secondary efficacy outcomes were ADHDRS-IV subscale scores and the Clinical Global Impression-Improvement (CGI-I) scale and the Clinical Global Impression-Severity (CGI-S) scale for ADHD (score or response rate). Other clinical or behavioral outcomes for assessing the efficacy of treatments for reducing ADHD symptoms were retrieved but are not reported here. Safety outcomes related to treatment of ADHD were collected as reported and included the frequency and nature of treatment-related adverse events, changes in body weight, blood pressure, and heart rate or pulse rate, and data on exacerbation of ADHD or comorbidity symptoms.

\section{Assessment of Study Quality}

An assessment of the risk of bias for each placebo-controlled RCT reporting effect sizes or for which effect sizes could be calculated for the primary outcome was conducted using the Cochrane Collaboration Risk of Bias tool [26]. The Cochrane Collaboration tool involves an evaluation of the risk of bias in the following domains: generation of allocation sequence, 
allocation concealment, masking of study personnel and participants, masking of outcome assessor, attrition, and selective outcome reporting. A study was defined as having a low risk of bias if zero domains were rated as high risk and $\leq 3$ domains were rated as unclear, or as having a moderate risk of bias if zero or one domain was rated as high risk but $\geq 4$ domains were rated as unclear; all other cases were assumed to have a high risk of bias [27].

\section{Statistical Analyses and Data Synthesis}

Quantitative data synthesis was not conducted because there were insufficient data to combine ADHD-RS-IV total scores or effect sizes. A systematic narrative synthesis is provided, with information presented in text and tables to summarize and explain the characteristics and findings of the included studies. Because quantitative data synthesis was not conducted, quantitative assessments of publication bias or assessments of outcome reporting bias were not conducted.

\section{RESULTS}

\section{Literature Search Output}

A total of 2177 publications/trials were retrieved (Fig. 1). The main reason for exclusion was duplicate publication, followed by publications/trials not conducted in patients with the comorbidities of interest. 72 publications/trials met all the eligibility criteria; of these, 69 reported on the primary and/or secondary efficacy outcomes $[17,18,20,28-46]$ and/or safety outcomes [16, 18, 19, 28-34, 36, 38-41, 43-91] and were included in the systematic review. Of the five meta-analyses and 37 placebo-controlled RCT publications/trials retrieved, 13 assessed patients with comorbid autism spectrum disorder, 14 with comorbid ODD, nine with comorbid Tourette's disorder and other tic disorders, and six with comorbid generalized anxiety disorder and/or MDD (Table 1). The mean age of patients enrolled in most metaanalyses and placebo-controlled RCTs ranged from 7.3 to 14.6 years, and $62.1-100 \%$ were male (Table 1).

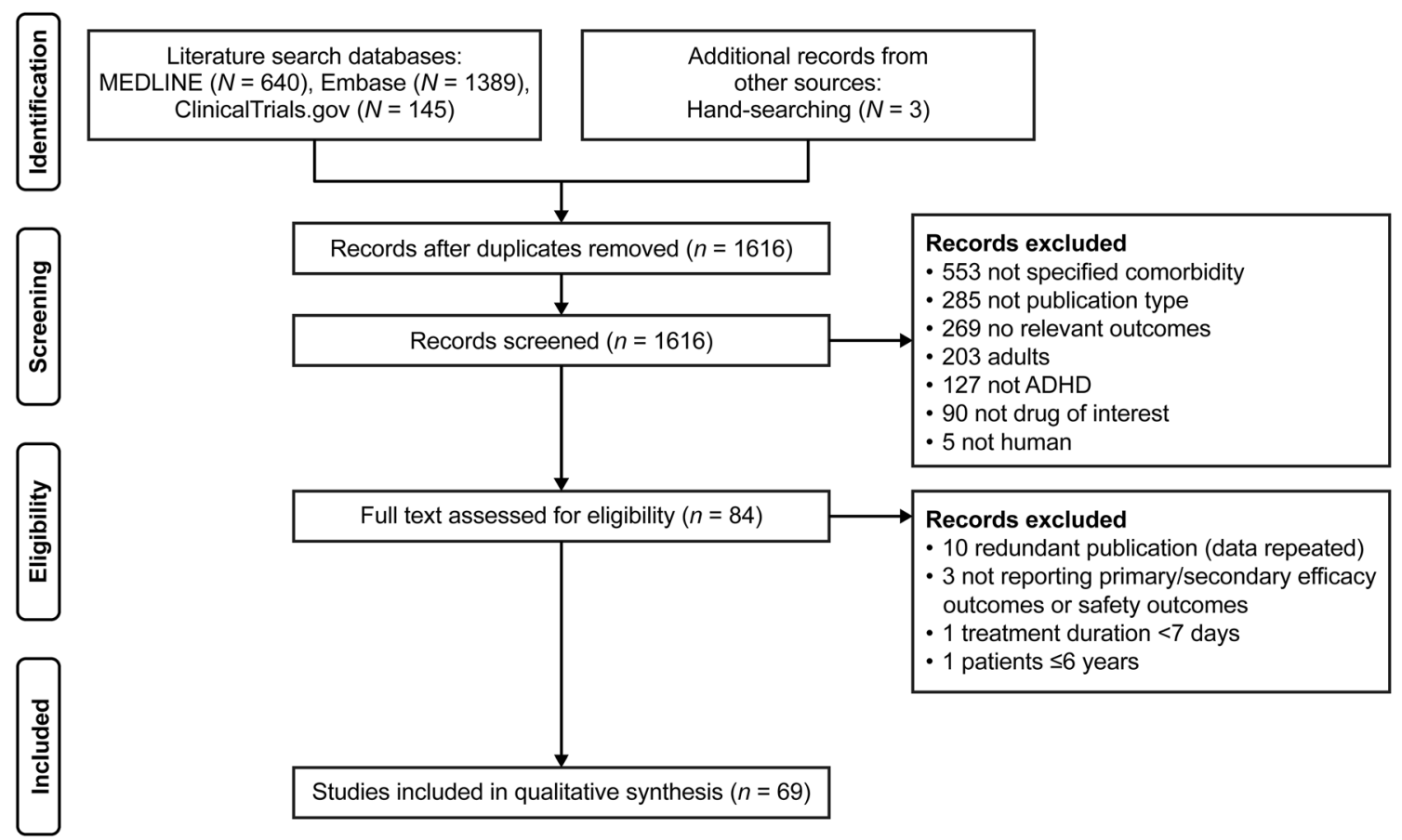

Fig. 1 Flow chart of publication selection process. $A D H D$ Attention-deficit hyperactivity disorder 


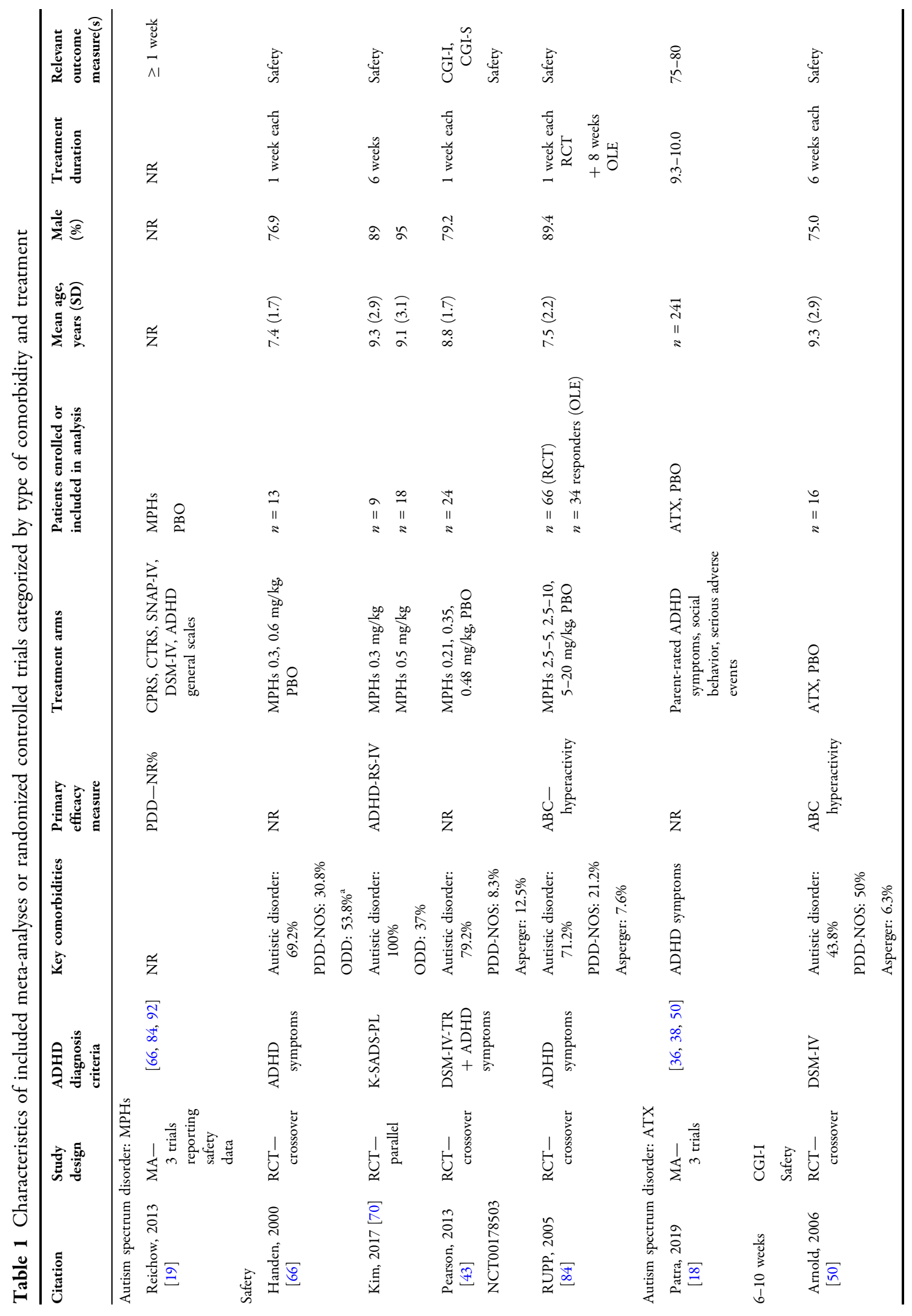




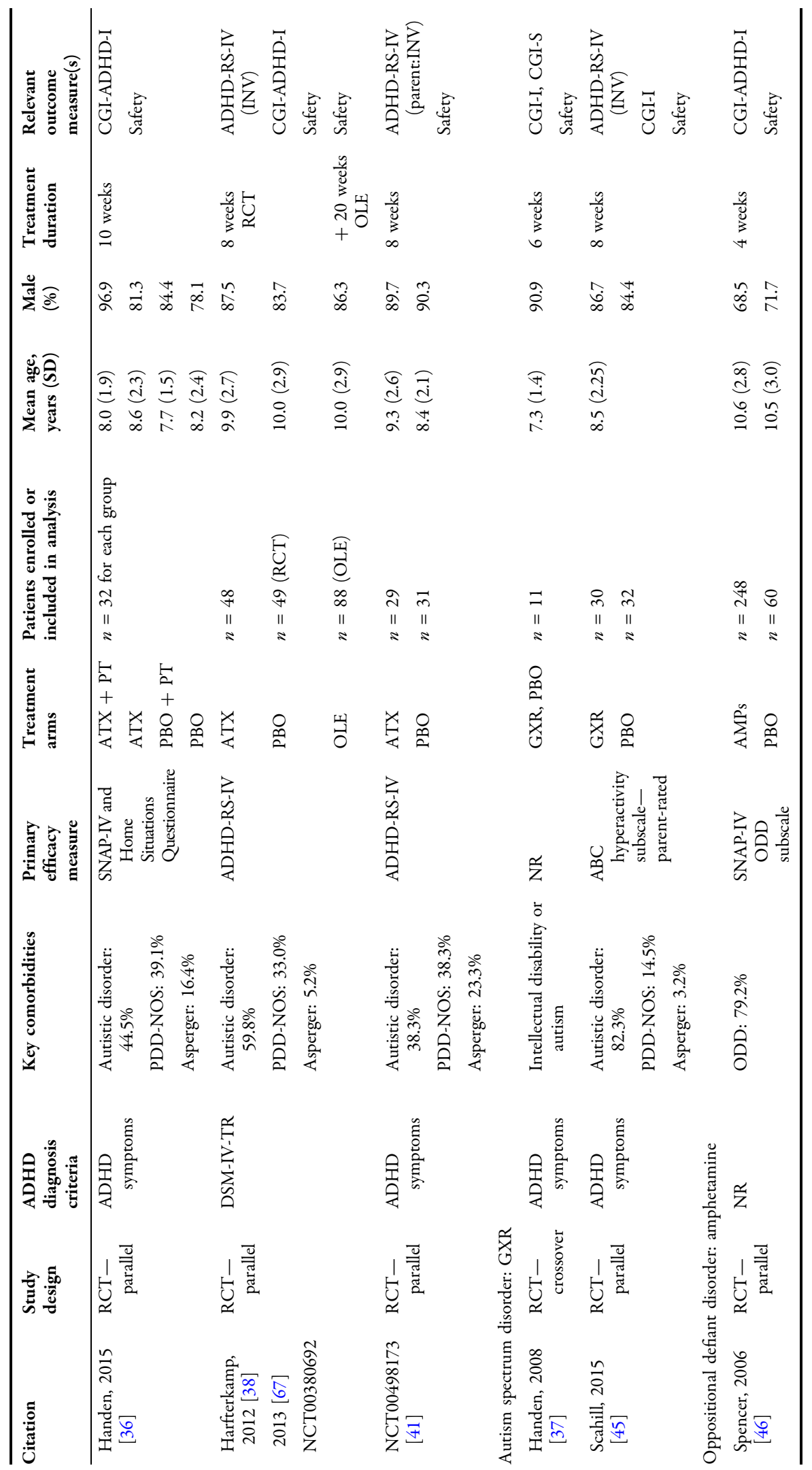




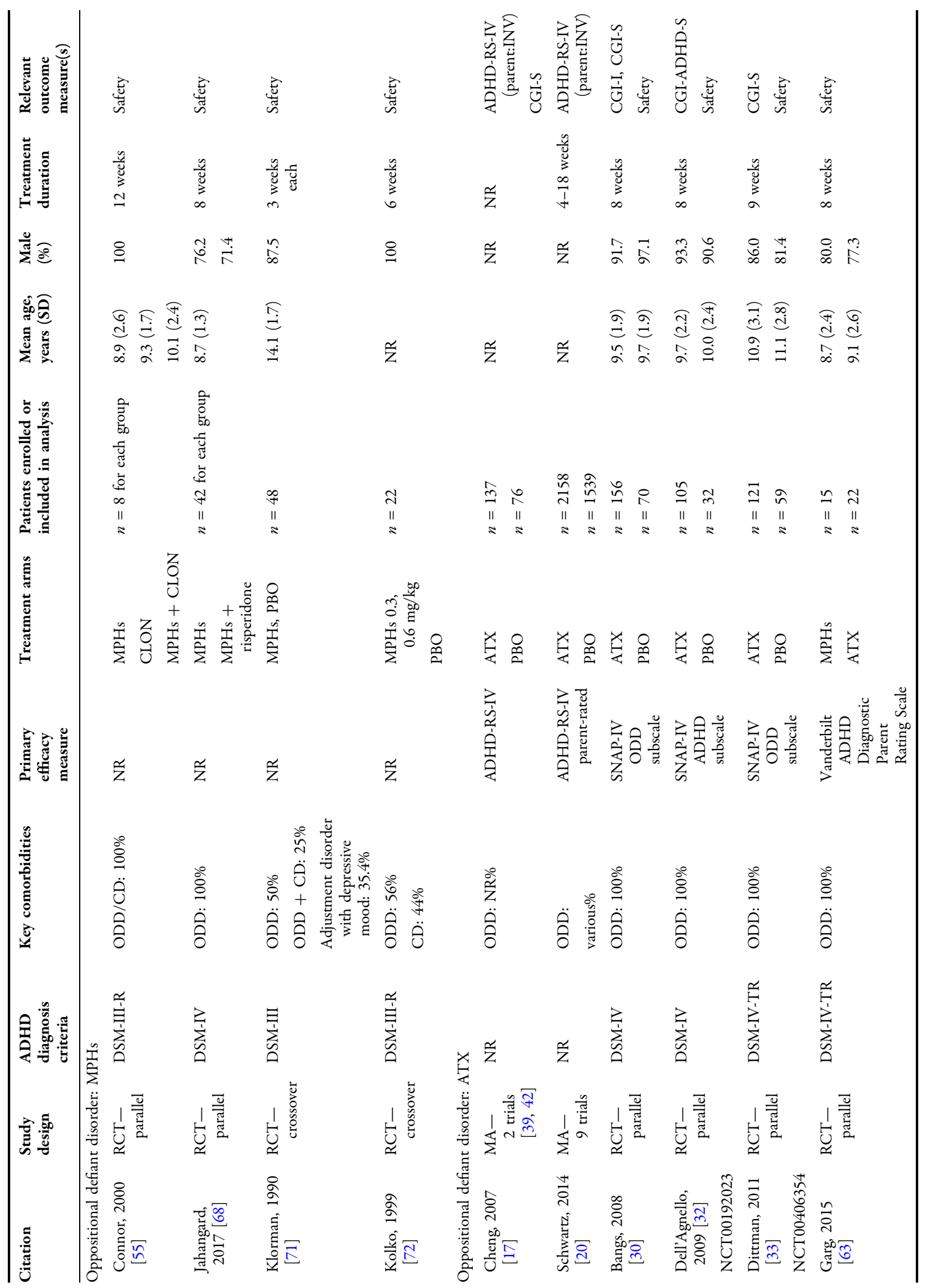




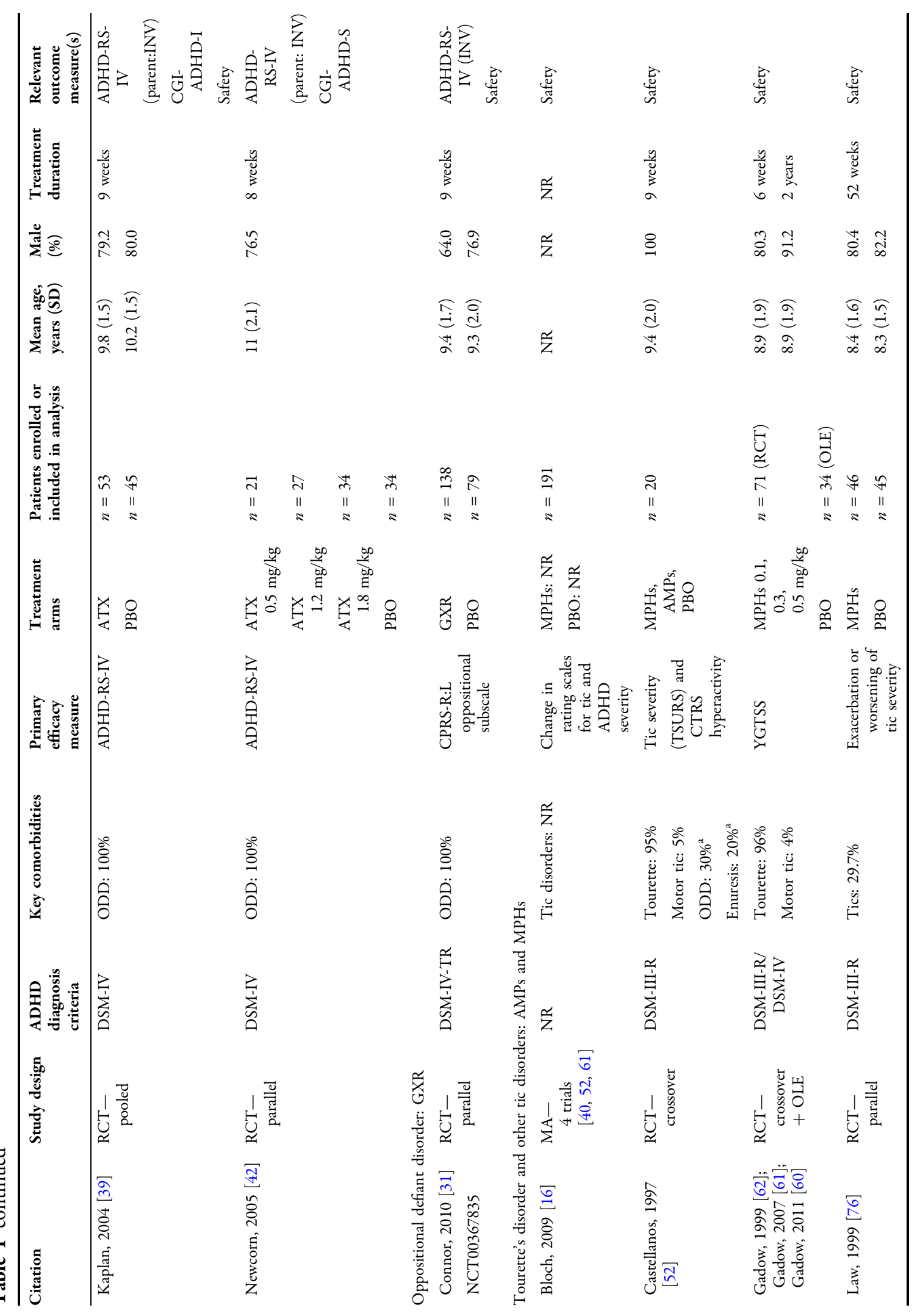




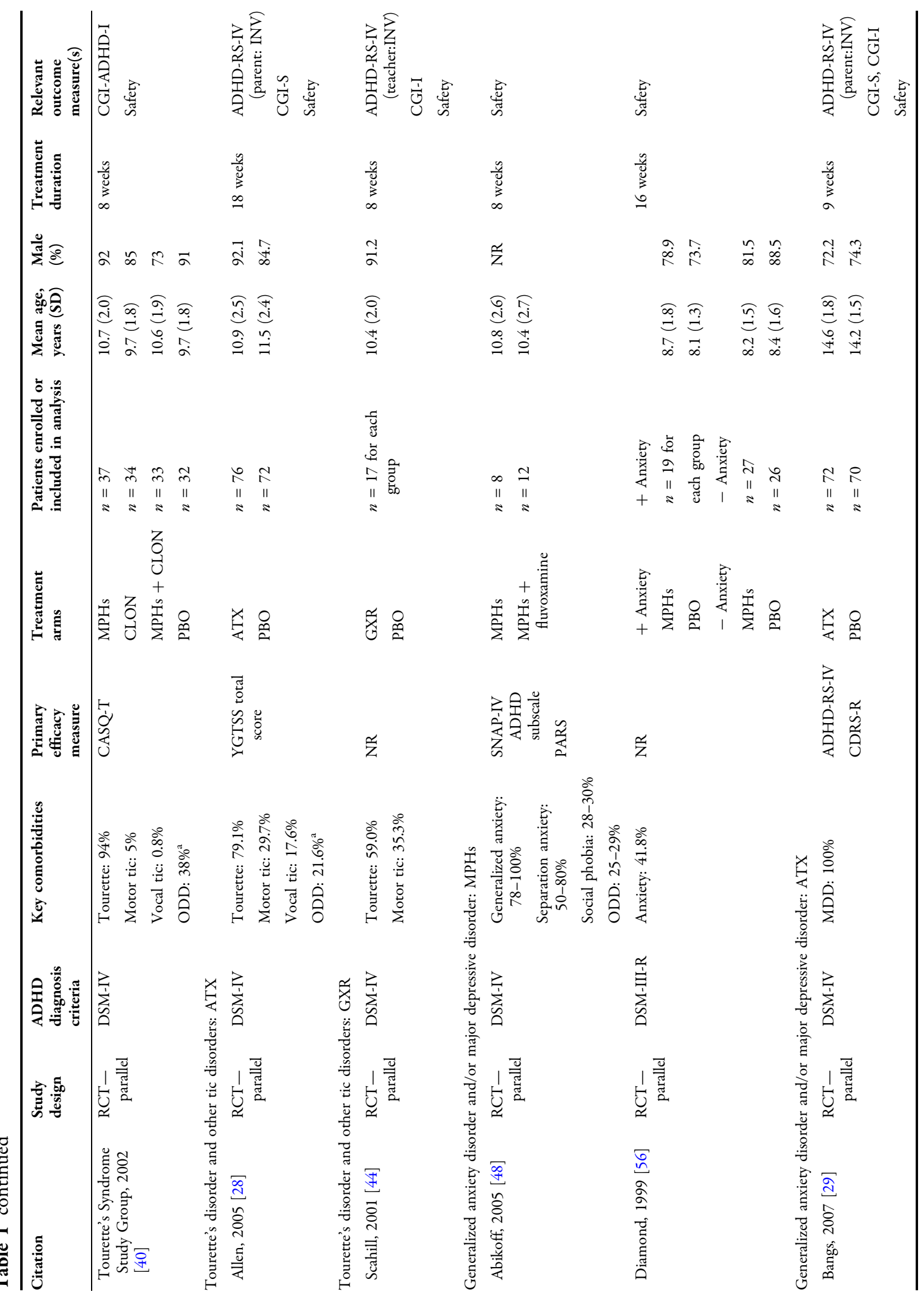




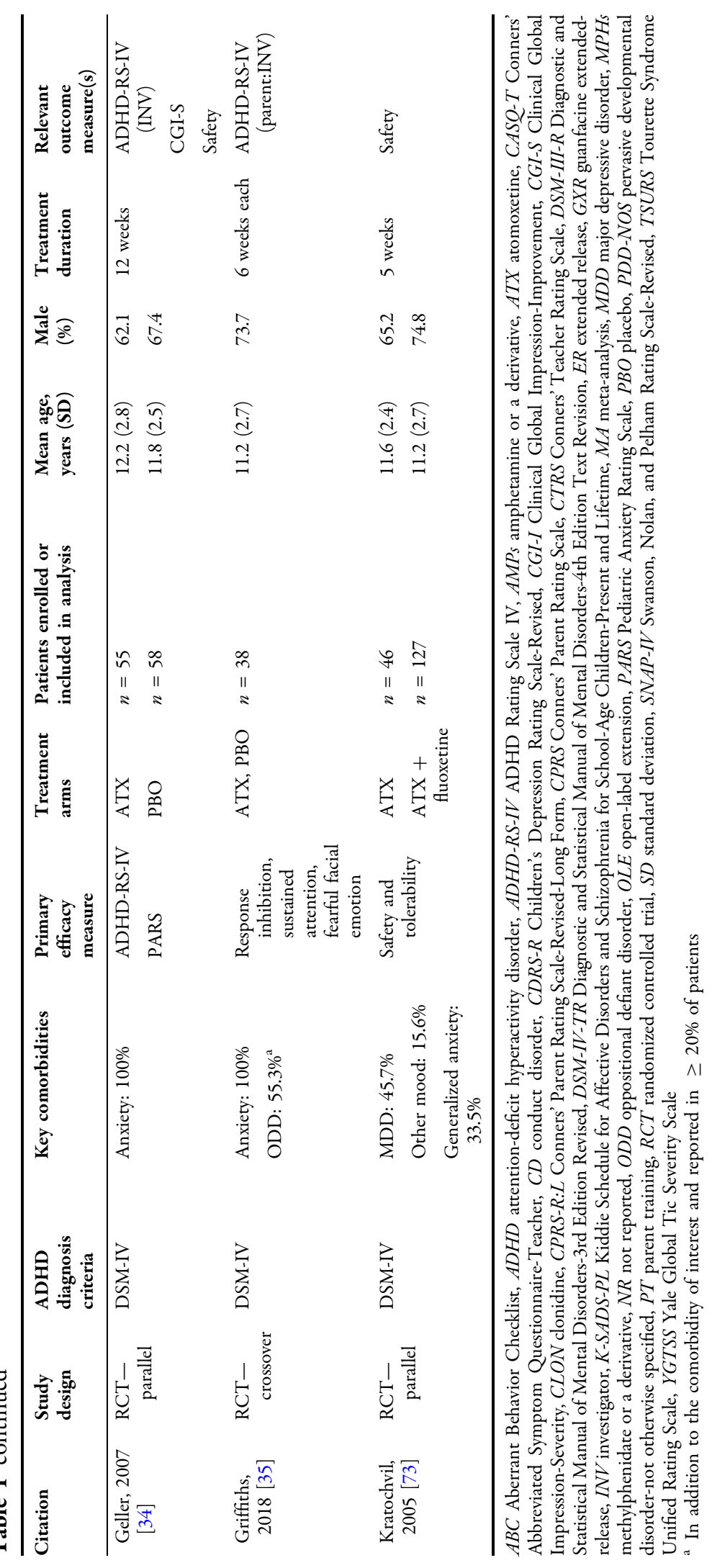




\section{Efficacy}

For primary and secondary efficacy, there were four meta-analyses [17, 18, 20, 39] and 18 placebo-controlled RCTs and associated extension studies [28-38, 40-46] (Table 1). Two metaanalyses/pooled analyses [17, 20] and 11 RCTs $[28,30,31,34,35,38,39,41,42,44,45]$ reported ADHD-RS-IV total scores (investigatorrated, parent-investigator-rated, teacher-investigator-rated). Effect sizes were available for ten RCTs [28, 29, 31, 34, 35, 38, 39, 42, 44, 45] (Table 2), and the overall risk of bias was rated as low for six RCTs, moderate for three RCTs, and high for one RCT for which the risk of bias was unclear for all domains (Table 2; ESM Table S1).

\section{Autism Spectrum Disorders}

Among the eligible studies, most patients were diagnosed with autism spectrum disorder (38.3-100\%), followed by pervasive developmental disorders-not otherwise specified (PDDNOS) $(8.3-50 \%)$, then Asperger's disorder (3.2-23.3\%) (Table 1). When reported, approximately one-third to half of patients also had comorbid ODD (Table 1).

There were no studies on AMPs that assessed patients with comorbid autism spectrum disorders and no placebo-controlled RCTs on MPHs that assessed ADHD symptoms with ADHD-RSIV (Table 1). There were two placebo-controlled RCTs on ATX [38, 41] and one placebo-controlled RCT on GXR [45] that assessed improvements in ADHD symptoms with ADHD-RS-IV. Of these, two studies [38, 45] showed significantly greater improvements in total scores and/or inattention and hyperactivity/impulsivity subscale scores with ATX and GXR compared with placebo (Table 2). Effect sizes for GXR and ATX were 2.03 and 0.87, respectively (Fig. 2).

There was one RCT on MPH [43], one metaanalysis [18] and two RCTs [36, 38] on ATX, and two RCTs on GXR $[37,45]$ that assessed secondary outcomes of CGI-I and/or CGI-S. CGI-I scores or response rates were consistently higher for MPHs, ATX, and GXR compared with placebo (ESM Table S2). There was one meta- analysis [18] of 193 patients who participated in a placebo-controlled RCT [38] and crossover trial [36]. Although the quality of the included studies was assessed as low, significantly greater improvements in CGI-I scores were confirmed for ATX compared with placebo [18]. In one RCT [43] there was a significantly greater improvement in CGI-S with MPHs compared with placebo (ESM Table S2).

\section{Oppositional Defiant Disorder}

Almost all meta-analyses [17, 20] and RCTs $[30,32,33,39,42]$ that assessed patients with ODD were focused on the efficacy of ATX (Table 1). There was one RCT on AMPs [46] that assessed a secondary efficacy outcome (CGIADHD-I), and no RCTs on MPHs that assessed the primary or secondary efficacy outcomes. Significantly greater improvements in ADHDRS-IV total scores and/or inattention and hyperactivity/impulsivity subscale scores were reported in two RCTs $[39,42]$ assessing ATX and in the one RCT [31] assessing GXR. Findings for ATX were confirmed by one meta-analysis [17] of patients in two RCTs $[39,42]$ and one metaanalysis [20] of a subgroup of patients with ADHD and ODD in nine clinical trials. The effect sizes ranged from 0.47 to 0.72 for ATX and was 0.92 for GXR (Fig. 2). One subgroup meta-analysis directly assessed the effects of ATX using ADHD-RS-IV total scores among 3697 children with and without ODD [20]. No significant differences for ATX compared with placebo were found, irrespective of the proportion of children with ODD in each subgroup ( $\leq 20 \%$ ODD, 20 to $<80 \%$ ODD, and $\geq 80 \%$ ODD) [20].

Findings from most eligible studies $[17,20,30,32,33,39,42]$ reporting CGI-I and CGI-S with ATX were consistent with the findings for ADHD-RS-IV (ESM Table S2). In the one RCT [46] that assessed the efficacy of AMPs, significantly greater improvement in CGIADHD-I was reported for AMPs compared with placebo (ESM Table S2).

\section{Tourette's Disorder and Other Tic Disorders} Of the one meta-analysis [16] and six RCTs $[28,40,44,52,60-62,76]$ (one with three 
publications) retrieved, only three [28, 40, 44] reported efficacy outcomes (Table 1). Most patients were diagnosed with Tourette's disorder (59-96.3\%) followed by motor or vocal tics (3.7-35.3\%) (Table 1). When reported, over onethird of patients also had ODD (Table 1).

There were no RCTs on AMPs or MPHs that assessed the primary or secondary efficacy outcomes. Significantly greater improvements in ADHD-RS-IV total scores and/or inattention and hyperactivity/impulsivity subscale scores were reported for the two RCTs assessing ATX and GXR (Table 2). In these studies, the effect sizes for GXR and ATX were 1.23 and 0.6, respectively (Fig. 2). In all eligible studies, significantly greater improvements in CGI-I or CGI-S were reported for MPHs [40], ATX [28], and GXR [44] compared with placebo (ESM Table S2).

\section{Generalized Anxiety Disorder and/or Major Depressive Disorder}

There were no studies on AMPs or GXR that assessed patients with generalized anxiety disorder or MDD and no placebo-controlled RCTs on MPHs that assessed the primary or secondary efficacy outcomes (Table 1). Of the three placebo-controlled RCTs $[29,34,35]$ that reported outcomes for patients with anxiety and MDD who were treated with ATX, significantly greater improvements in ADHD-RS-IV total scores and/or inattention and hyperactivity/ impulsivity subscale scores compared with placebo were reported (Table 2). When reported, the effect sizes for ATX ranged from 0.46 to 1 (Fig. 2). Significantly greater improvements in CGI-S were reported for patients with comorbid anxiety and significantly greater CGI-I response rates were reported for patients with comorbid MDD (ESM Table S2).

\section{Safety}

For safety, there were four meta-analyses/pooled analyses [16, 18, 19, 39], 33 RCTs and associated extension studies [28-34, 36, 38, 40, 41, 43-46, $48,50,52,55,56,60-63,66-68,70-73,76,84]$, 11 cohort studies $[53,54,58,69,74,79,83$, $86,87,90,91]$, and 16 case reports or case series $[47,49,51,57,59,64,65,75,77,78$,
$80-82,85,88,89]$. Most of the meta-analyses and RCTs were conducted in patients with ADHD and autism spectrum disorders or ODD, and more information was available on treatment with MPHs and ATX in these patients, with very few studies on AMPs or GXR (Table 1). Most RCTs included fewer than 50 patients per treatment arm and most were placebo-controlled, with very few studies directly comparing pharmacological treatments (Table 1).

\section{Adverse Events}

When reported, the numbers and types of adverse events with AMPs, MPHs, ATX, and GXR from patients with comorbid autism spectrum disorders (RCTs [18, 19, 37, 41, 43, 45] and cohort studies [54, 58, 69, 83, 86, 90, 91]) and ODD (RCTs [30-33, 39, 46, 55, 63, 71, 72] and cohort studies $[74,79,87])$ were consistent with the numbers and types of adverse events observed with these treatments in patients without comorbidities (ESM Table S3). Two meta-analyses assessed the safety of MPHs in patients with comorbid PDD [19] and ATX in patients with comorbid autistic disorder [18]. The meta-analysis of MPHs [19] included three RCTs [66, 84, 92] and showed that, compared with placebo, decreased appetite, insomnia, depressive symptoms, irritability, and social withdrawal were significantly associated with MPHs. The meta-analysis of ATX [18] included three RCTs [36, 38, 50] and showed that, compared with placebo, nausea and vomiting, decreased sleep, and decreased appetite were significantly associated with ATX. Most adverse events reported with ATX during active treatment decreased in frequency during longer-term treatment [67].

Very few RCTs or cohort studies reported adverse events in patients with comorbid tic disorders [28, 52, 53] or with anxiety and/or $\operatorname{MDD}[29,34,73]$. When reported, the adverse events associated with AMPs and MPHs [52], ATX [28, 29, 34, 73], and GXR [53] were consistent with the adverse events associated with these treatments in patients without comorbidities. One study found no differences in parent- or teacher-rated side effects between patients with and without comorbid anxiety after 4 months of treatment with MPHs following a titration phase [56]. There were no reports 
Table 2 Summary of efficacy for ADHD Rating Scale IV outcomes

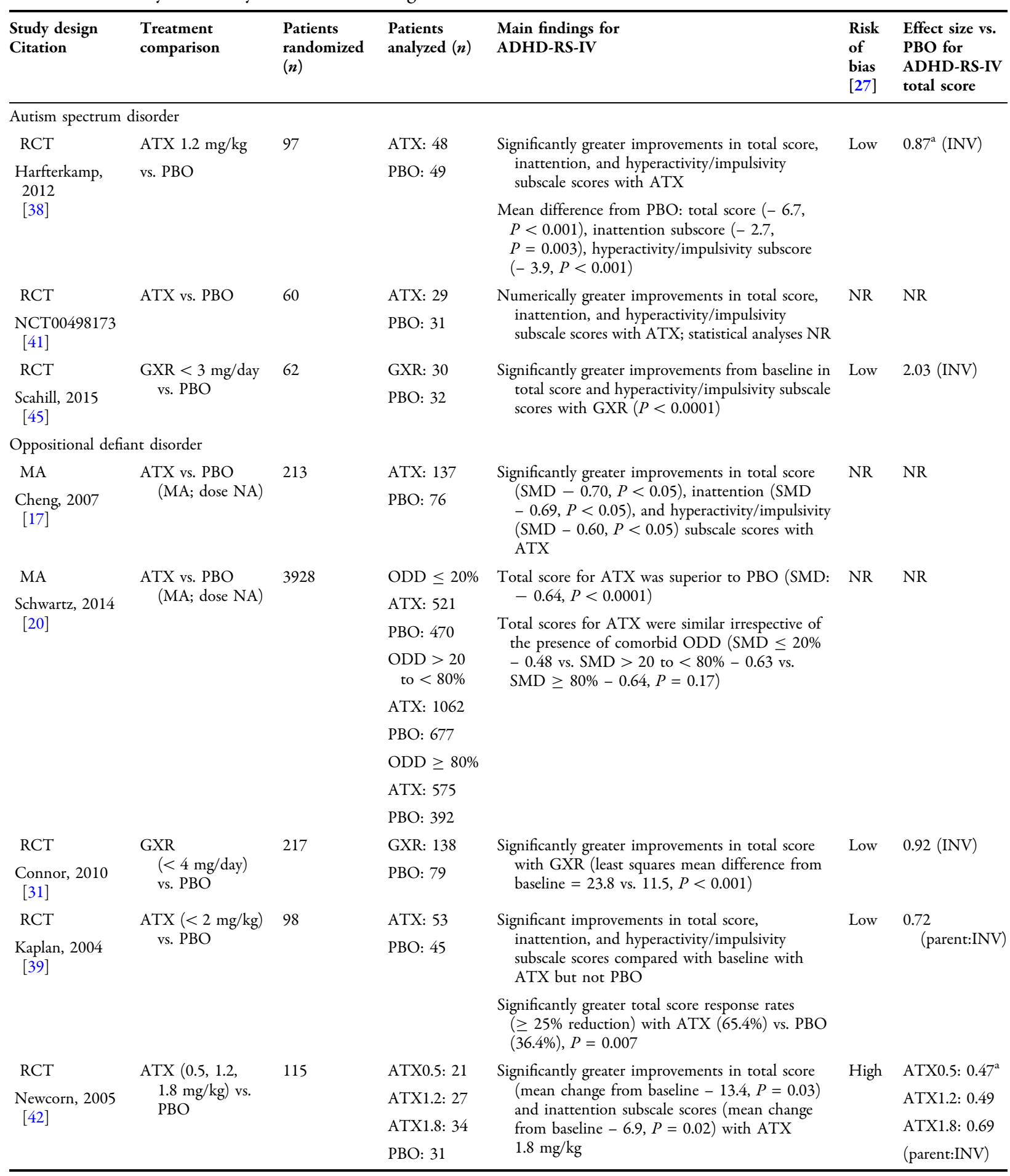


Table 2 continued

\begin{tabular}{|c|c|c|c|c|c|c|}
\hline $\begin{array}{l}\text { Study design } \\
\text { Citation }\end{array}$ & $\begin{array}{l}\text { Treatment } \\
\text { comparison }\end{array}$ & $\begin{array}{l}\text { Patients } \\
\text { randomized } \\
(n)\end{array}$ & $\begin{array}{l}\text { Patients } \\
\text { analyzed } \\
(n)\end{array}$ & $\begin{array}{l}\text { Main findings for } \\
\text { ADHD-RS-IV }\end{array}$ & $\begin{array}{l}\text { Risk } \\
\text { of } \\
\text { bias }\end{array}$ & $\begin{array}{l}\text { Effect size vs. } \\
\text { PBO for } \\
\text { ADHD-RS-IV } \\
\text { total score }\end{array}$ \\
\hline \multicolumn{7}{|c|}{ Tourette's disorder and other tic disorders } \\
\hline $\begin{array}{l}\text { RCT } \\
\text { Allen, } 2005 \\
{[28]}\end{array}$ & $\begin{array}{l}\text { ATX } \\
\quad(<1.5 \mathrm{mg} / \mathrm{kg}) \\
\text { vs. PBO }\end{array}$ & 148 & $\begin{array}{l}\text { ATX: } 76 \\
\text { PBO: } 72\end{array}$ & $\begin{array}{l}\text { Significantly greater improvements in total score, } \\
\text { inattention, and hyperactivity/impulsivity subscale } \\
\text { scores with ATX compared with PBO }\end{array}$ & Moderate & ${ }^{0.6}($ parent:INV) \\
\hline $\begin{array}{l}\text { RCT } \\
\text { Scahill, } 2001 \\
{[44]}\end{array}$ & $\begin{array}{l}\text { GXR } \\
\quad(<4 \mathrm{mg} / \text { day }) \\
\quad \text { vs. PBO }\end{array}$ & 34 & $\begin{array}{l}\text { GXR: } 17 \\
\text { PBO: } 17\end{array}$ & $\begin{array}{l}\text { Significantly greater improvements in (teacher-rated) } \\
\text { total score, inattention, and hyperactivity/ } \\
\text { impulsivity subscale scores with GXR }\end{array}$ & Moderate & $\begin{array}{l}1.23 \\
\text { (teacher:INV) }\end{array}$ \\
\hline \multicolumn{7}{|c|}{ Generalized anxiety disorder and major depressive disorder } \\
\hline $\begin{array}{l}\text { RCT } \\
\text { Bangs, } 2007 \\
{[29]}\end{array}$ & $\begin{array}{l}\text { ATX } \\
\quad(<1.8 \mathrm{mg} / \text { day }) \\
\text { vs. PBO }\end{array}$ & 142 & $\begin{array}{l}\text { ATX: } 72 \\
\text { PBO: } 70\end{array}$ & $\begin{array}{l}\text { Significantly greater improvements in total score } \\
\text { from baseline with ATX compared with PBO }\end{array}$ & Low & $\begin{array}{l}0.84 \\
\quad(\text { parent:INV })\end{array}$ \\
\hline $\begin{array}{l}\text { RCT } \\
\text { Geller, } 2007 \\
{[34]}\end{array}$ & $\begin{array}{l}\text { ATX } \\
\quad(<1.2 \mathrm{mg} / \mathrm{kg}) \\
\text { vs. PBO }\end{array}$ & 176 & $\begin{array}{l}\text { ATX: } 55 \\
\text { PBO: } 58\end{array}$ & $\begin{array}{l}\text { Significantly greater improvements in total score } \\
\text { (mean difference compared with PBO: }-10.5 \text {, } \\
P<0.001) \text {, inattention, and hyperactivity/ } \\
\text { impulsivity subscale scores with ATX } \\
\text { Significantly higher response rate }(\geq 25 \% \text { reduction } \\
\text { in total score from baseline) with ATX ( } 61.8 \% \text { vs. } \\
12.1 \%, P<0.001)\end{array}$ & Moderate & $1(\mathrm{INV})$ \\
\hline $\begin{array}{l}\text { RCT } \\
\text { Griffiths, } 2018 \\
{[35]}\end{array}$ & $\begin{array}{l}\text { ATX } \\
\quad(<1.4 \mathrm{mg} / \mathrm{kg}) \\
\text { vs. PBO }\end{array}$ & 140 & $\begin{array}{l}\text { ATX: } 38 \\
\text { PBO: } 38\end{array}$ & $\begin{array}{l}\text { Significantly greater improvements in ADHD-RS-IV } \\
\text { total score with ATX }\end{array}$ & Low & $\begin{array}{l}0.46 \\
\quad(\text { parent:INV})\end{array}$ \\
\hline
\end{tabular}

NA Not applicable, SMD standardized mean difference; for other abbreviations, see footnote of Table 1

${ }^{a}$ Calculated from published data

of treatment-emergent suicidal ideation in patients with comorbid anxiety [34] or comorbid MDD [29] and no exacerbation of depressive symptoms in patients with comorbid MDD [29] who were treated with ATX.

Adverse events reported in case reports of patients receiving MPHs included exacerbation of obsessive behavior [82], visual and/or auditory hallucinations $[47,49,51,64]$, severe agitation, and hyperactivity and/or irritability in three patients with ODD after switching from risperidone to MPHs [85]. Adverse events reported in case reports of patients receiving ATX included Raynaud's phenomenon [65] and onset of mania and auditory hallucinations when a patient titrated up to $40 \mathrm{mg} /$ day [78]. Lethargy, bradycardia, and hypertension were reported in a patient with ADHD and Tourette's disorder who ingested threefold his prescribed dose of GXR [57].
Cardiovascular Parameters and Body Weight Cardiovascular parameters and body weight were not consistently reported among the studies retrieved and were variable across studies (ESM Table S3). When reported, findings from RCTs were variable and showed that, compared with placebo, patients experienced decreased body weight with AMPs [46], MPHs [61, 71], and ATX [28-30, 32, 34], increased heart rate and/or blood pressure with MPHs [61] and ATX [28-30, 32, 34, 50], and decreased blood pressure and pulse rate with GXR [31, 45] during active treatment (ESM Table S4). Doserelated changes in body weight, blood pressure, and heart rate $[60,61]$ were reported in patients with tic disorders receiving MPHs during active treatment. However, following 2 years of maintenance therapy, there were no significant changes in expected body weight and, although 
significant increases in systolic blood pressure $(+6 \mathrm{mmHg})$ and heart rate (approx. $10 \mathrm{bpm})$ were reported, none were considered to be clinically relevant [62].

\section{Tic Exacerbation or Onset}

Exacerbation or onset of vocal and/or motor tics was reported among several cohort studies and case reports in patients treated with MPHs $[79,80,88]$ and ATX [75, 77, 81]. However, findings from several RCTs and a meta-analysis of MPH studies showed that worsening of tic severity or onset of new tics was not different from placebo in patients with comorbid tic disorders who were treated with MPHs or ATX $[16,28,40,60-62,76]$. For MPHs, worsening of tic severity was associated with higher drug doses $[40,52]$ and did not increase in frequency or severity during long-term maintenance therapy [62].

\section{DISCUSSION}

This is the first systematic review to conduct a comprehensive assessment of the efficacy and safety of treatments for children and adolescents with ADHD and psychiatric comorbidities. Despite the number of studies retrieved, most meta-analyses and RCTs were focused on the safety of MPHs or the efficacy and safety of ATX. In comparison, there was limited information on the efficacy of MPHs or the efficacy and safety of GXR, and very limited information on the use of AMPs.

Consistent with the findings from a comprehensive network meta-analysis in children and adolescents with ADHD [13], when reported, treatments were associated with significant improvements in ADHD symptoms during active treatment, regardless of comorbidity. Using clinician-rated composite measures for the change in severity of ADHD core symptoms, the network meta-analyses conducted by Cortese et al. [13] showed that effect sizes (Fig. 2b) were 1.02 for AMPs, 0.78 for MPHs, 0.67 for GXR, and 0.56 for ATX, which confirm the current European and North American recommendations for treatment of ADHD in children and adolescents [9]. Although Cortese et al. did not analyze treatments by specific comorbidities, they did conduct a sensitivity analysis excluding studies that solely enrolled patients with psychiatric/neurological comorbidities. In general, exclusion of these studies did not change the results, suggesting that comorbidities do not affect the efficacy of treatments for ADHD symptoms [13]. In the current review, which focused especially on children and adolescents with comorbidities, effect sizes for ADHD-RS-IV total scores across all comorbidities ranged from 0.46 to 1.0 for ATX and 0.92 to 2.0 for GXR. Subsequent to this literature review, a pooled analysis of four placebo-controlled RCTs enrolling children and adolescents with ADHD, of whom at least 10\% had ODD, has become available [93]. Findings from this analysis showed that dose-optimized GXR was associated with significant improvements in ADHD-RS-IV total scores in patients with and without ODD. The effect sizes for the pooled population were 0.88 and 0.73 for children and adolescents with and without ODD, respectively. A numerically higher effect size for patients with ODD was thought to be due to these patients having greater symptom severity than those without ODD and, therefore, greater capacity for improvement. Although effect sizes based on ADHD-RS-IV were not available for AMPs or MPHs in the current study, effect sizes based on CGI-S from a registry study of MPHs suggest that there may be variation in the effect of MPHs between comorbidities (ADHD only: 0.63; with comorbidities: 0.89 ; with ODD: 0.58; with anxiety: 1.61) [2]. In addition, a head-tohead comparison of ATX with MPHs [21], which pooled data for 1391 children with ADHD and comorbid ODD from seven RCTs, found no differences in the improvement in ADHD-RS-IV total scores or subscale scores between patients treated with ATX or MPHs.

In the current study, the types of adverse events reported for AMPs, MPHs, ATX, and GXR in children and adolescents with comorbidities were consistent with those reported from studies of children and adolescents predominantly without comorbidities [94-96], and there was no evidence to suggest major differences in the safety and tolerability of treatments by comorbidity. This is consistent with findings from the 
(a)

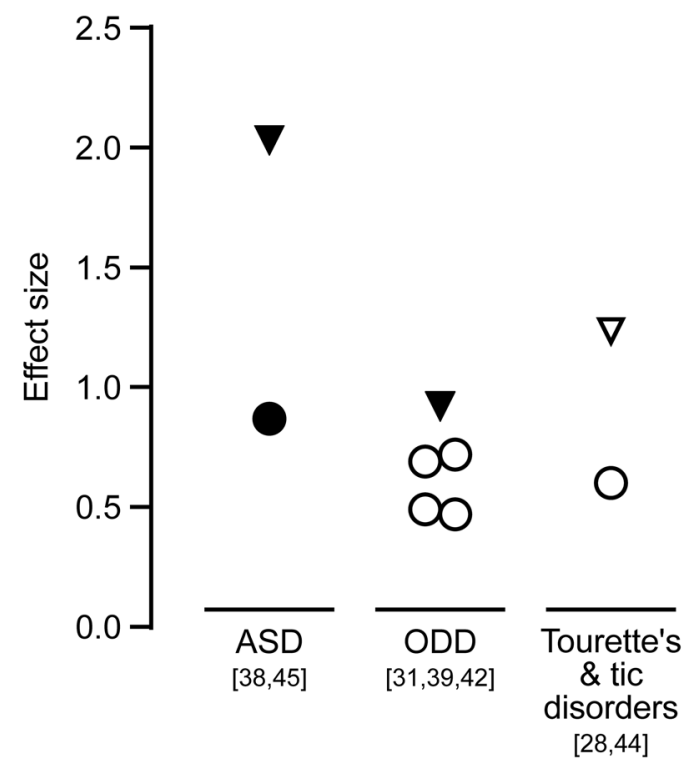

(b)

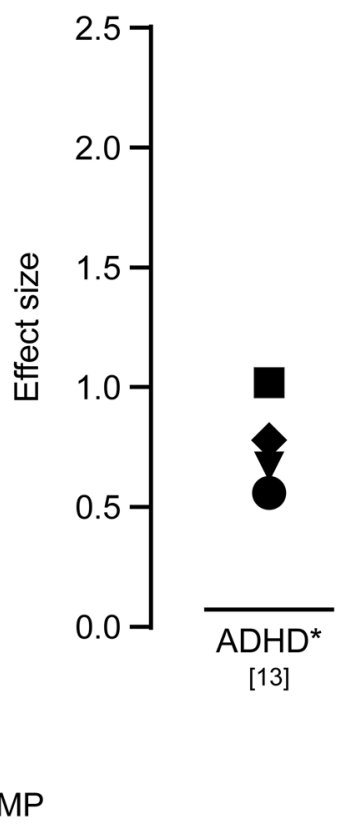

Fig. 2 Summary of effect sizes from a included studies for which the effect size (standardized mean difference) was reported [28, 29, 31, 34, 35, 39, 42, 44, 45] or could be calculated [38, 42] for the effect of treatment compared with placebo on ADHD symptoms (ADHD-RS-IV total scores) in children and adolescents with ADHD and at least one of the prespecified comorbidities, and $\mathbf{b}$ as reported by Cortese et al. [13] for analyses where studies of children with psychiatric and neurological comorbidities were not excluded. Asterisk indicates that the sensitivity analysis suggested that the presence of psychiatric

Italian National ADHD Registry study [94], which showed no consistent pattern for an increased rate of adverse events for children and adolescents with and without comorbidities. Furthermore, the sensitivity analysis in the Cortese et al. [13] network meta-analysis showed a slight improvement in tolerability for ADHD medications when studies that solely enrolled children and adolescents with psychiatric or neurological comorbidities were excluded. Although AMPs, MPHs, ATX, and GXR are associated with changes in body weight and/or cardiovascular factors [94-96], these factors were not well reported across the RCTs, particularly for AMPs and MPHs, which is likely to have contributed to reporting bias. In addition, comorbidities did not significantly affect the results when studies of children with psychiatric and neurological comorbidities were excluded. Filled symbols indicate investigator-rated ADHD-RS-IV scores; open symbols indicate parent- or teacher-investigator-rated ADHDRS-IV scores. $A D H D$ attention-deficit hyperactivity disorder, $A D H D-R S-I V$ ADHD Rating Scale IV, $A M P$ amphetamine, $A S D$ autism spectrum disorder, $A T X$ atomoxetine, $G X R$ guanfacine extended-release, $M D D$ major depressive disorder, $M P H$ methylphenidate, $O D D$ oppositional defiant disorder

although two crossover RCTs [43, 50] reported no significant differences between MPHs or ATX compared with placebo for changes in heart rate or blood pressure in children with autism spectrum disorder, these studies enrolled fewer than 25 patients and were not likely to be sufficiently powered for cardiovascular events. Despite this, a recent claims-based analysis from the USA assessed the risk of serious cardiovascular events in children with ADHD (2.2 million) or autism spectrum disorder $(326,221)$ who had been prescribed psychostimulants or ATX [97]. Findings from these large cohorts of children aged 3 to 18 years showed no increased risk of serious cardiovascular events in either cohort. As demonstrated by the exacerbation or 
onset of adverse events, including tics, obsessive thoughts, and agitation, reported in the case reports and cohort studies of children and adolescents receiving MPHs and ATX, the ability of children and adolescents with comorbidities to tolerate ADHD treatment in clinical practice was based on many factors, including the dose level and formulation (i.e., sustained or immediate release), whether doses were fixed or titrated, and individual responses. The results from these smaller reports are consistent with those from long-term clinical practice studies, such as the Italian National ADHD Registry study [94], and emphasize the need for ADHD treatments to be individualized to patients and prescribed at the lowest effective dose, as well as supporting current guidelines [7, 10, 11] that selection of pharmacotherapy should depend on the ability of patients to tolerate treatment and whether ADHD or the comorbidity or comorbid symptoms are to be treated first.

The key strength of this review was that it focused on studies of children and adolescents with multiple comorbidities in addition to $\mathrm{ADHD}$, and therefore represents the large proportion of patients with ADHD who require complex management strategies. In addition, most of the eligible placebo-controlled RCTs had a low to moderate risk of bias. However, the outcomes of this review are limited because very few studies were available that assessed efficacy using the primary ADHD core symptom rating scale, ADHD-RS-IV, and there was a high level of heterogeneity among the studies in the efficacy and safety outcomes reported. In particular, patient discontinuation is an important measure of the safety and tolerability of pharmacological treatments and may contribute to study bias. However, we were not able to include this measure because very few of the eligible studies reported dropout rates or reported dropout rates consistently between dose titration and dose maintenance. In addition, because there were very few studies that directly compared the efficacy and safety of ADHD treatments between children and adolescents with and without comorbidities, we were limited in the comparisons that we could make. It is important to acknowledge that, in addition to ADHD symptom response to treatment, an assessment of functional outcomes and comorbid symptoms are needed to comprehensively manage patients with comorbid ADHD. This is demonstrated by the diverse number of rating scales that were reported as the primary efficacy measure in this study (see Table 1). These scales ranged from those designed to measure ADHD symptom frequency, severity, and improvement to those specific to one symptom and those that included items associated with comorbid symptoms and functional outcomes [24]. As our objective was to compare treatment response specifically with respect to the severity of ADHD symptoms, we focused especially on the ADHD-RS-IV because it is a validated measure of treatment response for which a minimal clinically important difference has been defined [25].

\section{CONCLUSIONS}

Overall, findings from this systematic review showed that there is limited information available from placebo-controlled RCTs on the efficacy of drug treatments in reducing ADHD symptoms, in terms of ADHD-RS-IV in children and adolescents with ADHD and psychiatric comorbidities. The available evidence suggests that the safety profiles of the treatments assessed are consistent with the profiles in children without comorbidities. However, further studies are required to support evidence-based drug selection for children with ADHD and comorbidities and, in particular, there is a need for studies that compare the efficacy and safety of treatments in children and adolescents with and without comorbidities and between treatments.

\section{ACKNOWLEDGEMENTS}

Funding. This study was sponsored by Shire International $\mathrm{GmbH}$, Zug, Switzerland, a member of the Takeda group of companies, and Shionogi \& Co., Ltd., Osaka, Japan. The journal's Rapid Service Fee was funded by Shire International and Shionogi. Shionogi was 
involved in the development of the concept and protocol, review and approval of all studies for inclusion, analysis of the data, and in the drafting of the manuscript.

Medical Writing and Other Assistance. ProScribe-Envision Pharma Group was funded by Shire International and Shionogi to conduct the literature search and screening of publications against the eligibility criteria, and to provide medical writing assistance, which was conducted by Serina Stretton, PhD, CMPP, and Hiroko Ebina, PharmD.

Authorship. All named authors meet the International Committee of Medical Journal Editors (ICMJE) criteria for authorship for this article, take responsibility for the integrity of the work as a whole, and have given their approval for this version to be published.

Authors' Contributions. All authors participated in the interpretation of the study results, including the review and approval of all studies retrieved for inclusion, the drafting and/or critical revision of the manuscript, and approval of the final version. Noriyuki Naya, Toshinaga Tsuji, and Hirokazu Mishima were involved in the development of the concept for this review, Noa Tsujii, Toshinaga Tsuji, Hirokazu Mishima, and Junzo Iida were involved in development of the protocol, and Masakazu Fujiwara was involved in the analysis of the data.

Prior Presentation. The results of this systematic review were presented in a virtual format at the 116th Annual Meeting of the Japanese Society of Psychiatry and Neurology, September 28 to October 31, 2020.

Disclosures. Noa Tsujii has received personal fees outside the submitted work from Sumitomo Dainippon Pharma, Mitsubishi Tanabe Pharma, Yoshitomi Pharmaceutical Industries, Otsuka Pharmaceutical Co. Ltd, Shionogi \& Co., Ltd., Takeda Pharmaceutical Co., Ltd, and GlaxoSmithKline. Masahide Usami has no conflicts of interest to declare. Noriyuki Naya is an employee and stockholder of Shionogi \& Co., Ltd. Toshinaga Tsuji is an employee and stockholder of Shionogi \& Co., Ltd., and a stockholder of Takeda Pharmaceutical Co., Ltd. Hirokazu Mishima is an employee of Shionogi \& Co., Ltd. Junko Horie was an employee and stockholder of Shionogi \& Co., Ltd at the time the study was conducted. Junko Horie is currently affiliated with Takeda Pharmaceutical Co., Ltd, Tokyo, Japan. Masakazu Fujiwara is an employee and stockholder of Shionogi \& Co., Ltd. Junzo Iida has received personal fees outside the submitted work from Takeda Pharmaceutical Co., Ltd, Shionogi \& Co., Ltd., Eli Lilly Japan, and Janssen Pharmaceutical, Inc. At the time the study was conducted Junzo Iida was affiliated with the Faculty of Nursing at Nara Medical University, Kashihara, Nara, Japan. Junzo Iida is currently affiliated with the Nanfuaki Manyo Clinic, Kashihara, Nara, Japan.

Compliance with Ethics Guidelines. This article is based on previously conducted studies and does not contain any new studies with human participants or animals performed by any of the authors.

Data Availability. Data sharing is not applicable to this article as no datasets were generated or analyzed during the current study.

Open Access. This article is licensed under a Creative Commons Attribution-NonCommercial 4.0 International License, which permits any non-commercial use, sharing, adaptation, distribution and reproduction in any medium or format, as long as you give appropriate credit to the original author(s) and the source, provide a link to the Creative Commons licence, and indicate if changes were made. The images or other third party material in this article are included in the article's Creative Commons licence, unless indicated otherwise in a credit line to the material. If material is not included in the article's Creative Commons licence and your intended use is not permitted by statutory regulation or exceeds the permitted use, you will need to obtain permission directly from the copyright holder. To view a copy of this licence, visit http:// creativecommons.org/licenses/by-nc/4.0/. 


\section{REFERENCES}

1. Jensen CM, Steinhausen HC. Comorbid mental disorders in children and adolescents with attention-deficit/hyperactivity disorder in a large nationwide study. Atten Defic Hyperact Disord. 2015;7(1):27-38.

2. Reale L, Bartoli B, Cartabia M, et al. Comorbidity prevalence and treatment outcome in children and adolescents with ADHD. Eur Child Adolesc Psychiatry. $2017 ; 26(12): 1443-57$.

3. Fridman M, Banaschewski T, Sikirica V, Quintero J, Erder MH, Chen KS. Factors associated with caregiver burden among pharmacotherapy-treated children/adolescents with ADHD in the Caregiver Perspective on Pediatric ADHD survey in Europe. Neuropsychiatr Dis Treat. 2017;13:373-86.

4. Klassen AF, Miller A, Fine S. Health-related quality of life in children and adolescents who have a diagnosis of attention-deficit/hyperactivity disorder. Pediatrics. 2004;114(5):e541-7.

5. Sparrow EP, Erhardt D. Essentials of ADHD assessment for children and adolescents. In: Kaufman AS, Kaufman NL, series editors. Essentials of psychological assessment. Hoboken: Wiley; 2014.

6. Cortese M. Pharmacologic treatment of attention deficit-hyperactivity disorder. $\mathrm{N}$ Engl J Med. 2020;383(11):1050-6.

7. Canadian ADHD Resource Alliance (CADDRA). Canadian ADHD practice guidelines, 4.1 Edition. Toronto: CADDRA; 2020. https://www.caddra.ca/ canadian-adhd-practice-guidelines/. Accessed 14 Mar 2021.

8. Committee on Diagnosis and Treatment Guidelines of ADHD. Diagnosis and treatment guidelines on attention-deficit hyperactivity disorder (ADHD). 4th ed. Tokyo: Jiho; 2016.

9. National Institute for Care and Health Excellence. Attention deficit hyperactivity disorder: diagnosis and management. NICE guideline [NG87]. Published March 2018, last updated September 2019. https://www.nice.org.uk/guidance/ng87/chapter/ Recommendations. Accessed 3 Mar 2020.

10. Bolea-Alamañac B, Nutt DJ, Adamou M, et al. Evidence-based guidelines for the pharmacological management of attention deficit hyperactivity disorder: update on recommendations from the British Association for Psychopharmacology. J Psychopharmacol. 2014;28(3):179-203.

11. Wolraich ML, Hagan JF Jr, Allan C, et al. Subcommittee on children and adolescents with attention- deficit/hyperactive disorder. Clinical practice guideline for the diagnosis, evaluation, and treatment of attention-deficit/hyperactivity disorder in children and adolescents. Pediatrics. 2019;144(4): e20192528.

12. Catalá-López F, Hutton B, Núñez-Beltrán A, et al. The pharmacological and non-pharmacological treatment of attention deficit hyperactivity disorder in children and adolescents: a systematic review with network meta-analyses of randomised trials. PLoS ONE. 2017;12(7):e0180355.

13. Cortese S, Adamo N, Del Giovane C, et al. Comparative efficacy and tolerability of medications for attention-deficit hyperactivity disorder in children, adolescents, and adults: a systematic review and network meta-analysis. Lancet Psychiatry. 2018;5(9):727-38.

14. Li Y, Gao J, He S, Zhang Y, Wang Q. An evaluation on the efficacy and safety of treatments for attention deficit hyperactivity disorder in children and adolescents: a comparison of multiple treatments. Mol Neurobiol. 2017;54(9):6655-69.

15. Roskell NS, Setyawan J, Zimovetz EA, Hodgkins P. Systematic evidence synthesis of treatments for ADHD in children and adolescents: indirect treatment comparisons of lisdexamfetamine with methylphenidate and atomoxetine. Curr Med Res Opin. 2014;30(8):1673-85.

16. Bloch $\mathrm{MH}$, Panza KE, Landeros-Weisenberger A, Leckman JF. Meta-analysis: treatment of attentiondeficit/hyperactivity disorder in children with comorbid tic disorders. J Am Acad Child Adolesc Psychiatry. 2009;48(9):884-93.

17. Cheng JYW, Chen RYL, Ko JSN, Ng EML. Efficacy and safety of atomoxetine for attention-deficit/hyperactivity disorder in children and adolescentsmeta-analysis and meta-regression analysis. Psychopharmacology. 2007;194:197-209.

18. Patra S, Nebhinani N, Viswanathan A, Kirubakaran R. Atomoxetine for attention deficit hyperactivity disorder in children and adolescents with autism: a systematic review and meta-analysis. Autism Res. 2019;12(4):542-52.

19. Reichow B, Volkmar FR, Bloch MH. Systematic review and meta-analysis of pharmacological treatment of the symptoms of attention-deficit/hyperactivity disorder in children with pervasive developmental disorders. J Autism Dev Disord. 2013;43(10):2435-41.

20. Schwartz S, Correll CU. Efficacy and safety of atomoxetine in children and adolescents with attention-deficit/hyperactivity disorder: results from a comprehensive meta-analysis and metaregression. 
J Am Acad Child Adolesc Psychiatry. 2014;53(2): 174-87.

21. van Wyk GW, Hazell PL, Kohn MR, Granger RE, Walton RJ. How oppositionality, inattention, and hyperactivity affect response to atomoxetine versus methylphenidate: a pooled meta-analysis. J Atten Disord. 2012;16(4):314-24.

22. Villas-Boas CB, Chierrito D, Fernandez-Llimos F, Tonin FS, Sanches ACC. Pharmacological treatment of attention-deficit hyperactivity disorder comorbid with an anxiety disorder: a systematic review. Int Clin Psychopharmacol. 2019;34(2):57-64.

23. Hutchison SL, Ghuman JK, Ghuman HS, Karpov I, Schuster JM. Efficacy of atomoxetine in the treatment of attention-deficit hyperactivity disorder in patients with common comorbidities in children, adolescents and adults: a review. Ther Adv Psychopharmacol. 2016;6(5):317-34.

24. Collett BR, Ohan JL, Myers KM. Ten-year review of rating scales. V: scales assessing attention-deficit/ hyperactivity disorder. J Am Acad Child Adolesc Psychiatry. 2003;42(9):1015-37.

25. Zhang S, Faries DE, Vowles M, Michelson D. ADHD Rating Scale IV: psychometric properties from a multinational study as a clinician-administered instrument. Int $\mathrm{J}$ Methods Psychiatr Res. 2005;14(4):186-201.

26. Higgins JP, Altman DG, Gøtzsche PC, et al. The Cochrane Collaboration's tool for assessing risk of bias in randomised trials. BMJ. 2011;343:d5928.

27. Furukawa TA, Salanti G, Atkinson LZ, et al. Comparative efficacy and acceptability of first-generation and second-generation antidepressants in the acute treatment of major depression: protocol for a network meta-analysis. BMJ Open. 2016;6(7): e010919.

28. Allen AJ, Kurlan RM, Gilbert DL, et al. Atomoxetine treatment in children and adolescents with ADHD and comorbid tic disorders. Neurology. 2005;65(12):1941-9.

29. Bangs ME, Emslie GJ, Spencer TJ, et al. Efficacy and safety of atomoxetine in adolescents with attention-deficit/hyperactivity disorder and major depression. J Child Adolesc Psychopharmacol. 2007;17(4):407-19.

30. Bangs ME, Hazell P, Danckaerts M, et al. Atomoxetine for the treatment of attention-deficit/hyperactivity disorder and oppositional defiant disorder. Pediatrics. 2008;121:e314-20.

31. Connor DF, Findling RL, Kollins SH, et al. Effects of guanfacine extended release on oppositional symptoms in children aged 6-12 years with attention-deficit hyperactivity disorder and oppositional symptoms: a randomized, double-blind, placebocontrolled trial. CNS Drugs. 2010;24(9):755-68.

32. Dell'Agnello G, Maschietto D, Bravaccio C, et al. Atomoxetine hydrochloride in the treatment of children and adolescents with attention-deficit/ hyperactivity disorder and comorbid oppositional defiant disorder: a placebo-controlled Italian study. Eur Neuropsychopharmacol. 2009;19(11):822-34.

33. Dittmann RW, Schacht A, Helsberg K, et al. Atomoxetine versus placebo in children and adolescents with attention-deficit/hyperactivity disorder and comorbid oppositional defiant disorder: a double-blind, randomized, multicenter trial in Germany. J Child Adolesc Psychopharmacol. 2011;21(2):97-110.

34. Geller D, Donnelly C, Lopez F, et al. Atomoxetine treatment for pediatric patients with attentiondeficit/hyperactivity disorder with comorbid anxiety disorder. J Am Acad Child Adolesc Psychiatry. 2007;46(9):1119-27.

35. Griffiths KR, Leikauf JE, Tsang TW, et al. Response inhibition and emotional cognition improved by atomoxetine in children and adolescents with ADHD: the ACTION randomized controlled trial. J Psychiatr Res. 2018;102:57-64.

36. Handen BL, Aman MG, Arnold LE, et al. Atomoxetine, parent training, and their combination in children with autism spectrum disorder and attention-deficit/hyperactivity disorder. J Am Acad Child Adolesc Psychiatry. 2015;54(11):905-15.

37. Handen BL, Sahl R, Hardan AY. Guanfacine in children with autism and/or intellectual disabilities. J Dev Behav Pediatr. 2008;29(4):303-8.

38. Harfterkamp M, van de Loo-Neus G, Minderaa RB, et al. A randomized double-blind study of atomoxetine versus placebo for attention-deficit/hyperactivity disorder symptoms in children with autism spectrum disorder. J Am Acad Child Adolesc Psychiatry. 2012;51(7):733-41.

39. Kaplan S, Heiligenstein J, West S, et al. Efficacy and safety of atomoxetine in childhood attention-deficit/hyperactivity disorder with comorbid oppositional defiant disorder. J Atten Disord. 2004;8(2): $45-52$.

40. Tourette's Syndrome Study Group. Treatment of ADHD in children with tics: A randomized controlled trial. Neurology. 2002;58(4):527-36.

41. NCT00498173. Effectiveness of atomoxetine in treating ADHD symptoms in children and 
adolescents with autism. 2017. https://clinicaltrials. gov/ct2/show/NCT00498173. Accessed 4 Mar 2020.

42. Newcorn JH, Spencer TJ, Biederman J, Milton DR, Michelson D. Atomoxetine treatment in children and adolescents with attention-deficit/hyperactivity disorder and comorbid oppositional defiant disorder. J Am Acad Child Adolesc Psychiatry. $2005 ; 44(3): 240-8$.

43. Pearson DA, Santos CW, Aman MG, et al. Effects of extended release methylphenidate treatment on ratings of attention-deficit/hyperactivity disorder (ADHD) and associated behavior in children with autism spectrum disorders and ADHD symptoms. J Child Adolesc Psychopharmacol. 2013;23(5): 337-51.

44. Scahill L, Chappell PB, Kim YS, et al. A placebocontrolled study of guanfacine in the treatment of children with tic disorders and attention deficit hyperactivity disorder. Am J Psychiatry. 2001;158(7):1067-74.

45. Scahill L, McCracken JT, King BH, et al. Extendedrelease guanfacine for hyperactivity in children with autism spectrum disorder. Am J Psychiatry. 2015;172(12):1197-206.

46. Spencer TJ, Abikoff HB, Connor DF, et al. Efficacy and safety of mixed amphetamine salts extended release (adderall XR) in the management of oppositional defiant disorder with or without comorbid attention-deficit/hyperactivity disorder in schoolaged children and adolescents: a 4-week, multicenter, randomized, double-blind, parallel-group, placebo-controlled, forced-dose-escalation study. Clin Ther. 2006;28(3):402-18.

47. Abali O, Mukaddes NM. Methylphenidate induced hallucinations: case report. Klinik Psikofarmakoloji Bülteni. 2007;17:195-7.

48. Abikoff H, McGough J, Vitiello B, et al. Sequential pharmacotherapy for children with comorbid attention-deficit/hyperactivity and anxiety disorders. J Am Acad Child Adolesc Psychiatry. 2005;44(5):418-27.

49. Aktepe E, Erdoğan Y. Methylphenidate-induced visual hallucinations in a child with autism spectrum disorder and ADHD: a case report. Anadolu Psikiyatri Derg. 2017;18(Suppl 1):53-5.

50. Arnold LE, Aman MG, Cook AM, et al. Atomoxetine for hyperactivity in autism spectrum disorders: placebo-controlled crossover pilot trial. J Am Acad Child Adolesc Psychiatry. 2006;45(10):1196-205.

51. Atabay E, Rodopman AA. Hallusinosis due to methylphenidate overdose in an eight-year-old child: a case report. Marmara Med J. 2016;29(3): 177-80.

52. Castellanos FX, Giedd JN, Elia J, et al. Controlled stimulant treatment of ADHD and comorbid Tourette's syndrome: effects of stimulant and dose. J Am Acad Child Adolesc Psychiatry. 1997;36(5):589-96.

53. Chappell PB, Riddle MA, Scahill L, et al. Guanfacine treatment of comorbid attention-deficit hyperactivity disorder and Tourette's syndrome: preliminary clinical experience. J Am Acad Child Adolesc Psychiatry. 1995;34(9):1140-6.

54. Charnsil C. Efficacy of atomoxetine in children with severe autistic disorders and symptoms of ADHD: an open-label study. J Atten Disord. 2011;15(8):684-9.

55. Connor DF, Barkley RA, Davis HT. A pilot study of methylphenidate, clonidine, or the combination in ADHD comorbid with aggressive oppositional defiant or conduct disorder. Clin Pediatr. 2000;39: $15-25$.

56. Diamond IR, Tannock R, Schachar RJ. Response to methylphenidate in children with ADHD and comorbid anxiety. J Am Acad Child Adolesc Psychiatry. 1999;38(4):402-9.

57. Fein DM, Hafeez ZF, Cavagnaro C. An overdose of extended-release guanfacine. Pediatr Emerg Care. 2013;29:929-31.

58. Fernández-Jaén A, Fernández-Mayoralas DM, Calleja-Pérez B, Muñoz-Jareño N, Campos Díaz MR, López-Arribas S. Efficacy of atomoxetine for the treatment of ADHD symptoms in patients with pervasive developmental disorders: a prospective, open-label study. J Atten Disord. 2013;17(6): 497-505.

59. Findling RL. Open-label treatment of comorbid depression and attentional disorders with co-administration of serotonin reuptake inhibitors and psychostimulants in children, adolescents, and adults: a case series. J Child Adolesc Psychopharmacol. 1996;6(3):165-75.

60. Gadow KD, Nolan EE. Methylphenidate and comorbid anxiety disorder in children with both chronic multiple tic disorder and ADHD. J Atten Disord. 2011;15(3):246-56.

61. Gadow KD, Sverd J, Nolan EE, Sprafkin J, Schneider J. Immediate-release methylphenidate for ADHD in children with comorbid chronic multiple tic disorder. J Am Acad Child Adolesc Psychiatry. 2007;46(7):840-8.

62. Gadow KD, Sverd J, Sprafkin J, Nolan EE, Grossman S. Long-term methylphenidate therapy in children 
with comorbid attention-deficit hyperactivity disorder and chronic multiple tic disorder. Arch Gen Psychiatry. 1999;56(4):330-6.

63. Garg J, Arun P, Chavan BS. Comparative efficacy of methylphenidate and atomoxetine in oppositional defiant disorder comorbid with attention deficit hyperactivity disorder. Int J Appl Basic Med Res. 2015;5(2):114-8.

64. Goetz M, Příhodová I, Hrdlička M. Long lasting complex nocturnal hallucinations during osmotic release oral system (OROS) methylphenidate treatment in a 7-year old girl. Neuro Endocrinol Lett. 2011;32(5):101-4.

65. Gülle ZN, Karayagmurlu A, Coskun M. Raynaud's phenomenon related with atomoxetine treatment in a child with autism and attention-deficit/hyperactivity disorder. J Child Adolesc Psychopharmacol. 2019;29(8):649-50.

66. Handen BL, Johnson CR, Lubetsky M. Efficacy of methylphenidate among children with autism and symptoms of attention-deficit hyperactivity disorder. J Autism Dev Disord. 2000;30(3):245-55.

67. Harfterkamp M, Buitelaar JK, Minderaa RB, van de Loo-Neus G, van der Gaag RJ, Hoekstra PJ. Longterm treatment with atomoxetine for attentiondeficit/hyperactivity disorder symptoms in children and adolescents with autism spectrum disorder: an open-label extension study. J Child Adolesc Psychopharmacol. 2013;23(3):194-9.

68. Jahangard L, Akbarian S, Haghighi M, et al. Children with ADHD and symptoms of oppositional defiant disorder improved in behavior when treated with methylphenidate and adjuvant risperidone, though weight gain was also observed-results from a randomized, double-blind, placebo-controlled clinical trial. Psychiatry Res. 2017;251:182-91.

69. Kilincaslan A, Mutluer TD, Pasabeyoglu B, Tutkunkardas MD, Mukaddes NM. Effects of atomoxetine in individuals with attention-deficit/hyperactivity disorder and low-functioning autism spectrum disorder. J Child Adolesc Psychopharmacol. 2016;26(9):798-806.

70. Kim SJ, Shonka S, French WP, Strickland J, Miller L, Stein MA. Dose-response effects of long-acting liquid methylphenidate in children with attention deficit/hyperactivity disorder (ADHD) and autism spectrum disorder (ASD): a pilot study. J Autism Dev Disord. 2017;47(8):2307-13.

71. Klorman R, Brumaghim JT, Fitzpatrick PA, Borgstedt AD. Clinical effects of a controlled trial of methylphenidate on adolescents with attention deficit disorder. J Am Acad Child Adolesc Psychiatry. 1990;29(5):702-9.
72. Kolko DJ, Bukstein OG, Barron J. Methylphenidate and behavior modification in children with ADHD and comorbid ODD or CD: main and incremental effects across settings. J Am Acad Child Adolesc Psychiatry. 1999;38(5):578-86.

73. Kratochvil CJ, Newcorn JH, Arnold LE, et al. Atomoxetine alone or combined with fluoxetine for treating ADHD with comorbid depressive or anxiety symptoms. J Am Acad Child Adolesc Psychiatry. 2005;44(9):915-24.

74. Kronenberger WG, Giauque AL, Lafata DE, Bohnstedt BN, Maxey LE, Dunn DW. Quetiapine addition in methylphenidate treatment-resistant adolescents with comorbid attention-deficit/hyperactivity disorder, conduct/oppositional-defiant disorder, and aggression: a prospective, open-label study. J Child Adolesc Psychopharmacol. 2007;17(3):334-47.

75. Küçükköse M, Özbaran NB, Köse SG. Motor tics due to atomoxetine use: a case report. Klinik Psikofarmakoloji Bulteni. 2011;21(4):364-7.

76. Law SF, Schachar RJ. Do typical clinical doses of methylphenidate cause tics in children treated for attention-deficit hyperactivity disorder? J Am Acad Child Adolesc Psychiatry. 1999;38(8):944-51.

77. Ledbetter M. Atomoxetine use associated with onset of a motor tic. J Child Adolesc Psychopharmacol. 2005;15(2):331-3.

78. Liu CC, Lan CC, Chen YS. Atomoxetine-induced mania with auditory hallucination in an 8-year-old boy with attention-deficit/hyperactivity disorder and tic disorder. J Child Adolesc Psychopharmacol. 2014;24(8):466-7.

79. Masi G, Manfredi A, Nieri G, Muratori P, Pfanner C, Milone A. A naturalistic comparison of methylphenidate and risperidone monotherapy in drugnaive youth with attention-deficit/hyperactivity disorder comorbid with oppositional defiant disorder and aggression. J Clin Psychopharmacol. 2017;37(5):590-4.

80. Okazaki K, Yamamuro K, Iida J, Kishimoto T. Guanfacine monotherapy for ADHD/ASD comorbid with Tourette syndrome: a case report. Ann Gen Psychiatry. 2019;18:2.

81. Párraga HC, Párraga MI, Harris DK. Tic exacerbation and precipitation during atomoxetine treatment in two children with attention-deficit hyperactivity disorder. Int J Psychiatry Med. 2007;37(4):415-24.

82. Pedraza JD, Coffey B. Obsessive-compulsive disorder and comorbid attention-deficit/hyperactivity disorder: a complex diagnostic disentanglement 
and treatment. J Child Adolesc Psychopharmacol. 2013;23(6):419-22.

83. Posey DJ, Wiegand RE, Wilkerson J, Maynard M, Stigler KA, McDougle CJ. Open-label atomoxetine for attention-deficit/hyperactivity disorder symptoms associated with high-functioning pervasive developmental disorders. J Child Adolesc Psychopharmacol. 2006;16(5):599-610.

84. Research Units on Pediatric Psychopharmacology (RUPP) Autism Network. Randomized, controlled, crossover trial of methylphenidate in pervasive developmental disorders with hyperactivity. Arch Gen Psychiatry. 2005;62(11):1266-74.

85. Sabuncuoglu O. Risperidone-to-methylphenidate switch reaction in children: three cases. J Psychopharmacol. 2007;21(2):216-9.

86. Santosh PJ, Baird G, Pityaratstian N, Tavare E, Gringras P. Impact of comorbid autism spectrum disorders on stimulant response in children with attention deficit hyperactivity disorder: a retrospective and prospective effectiveness study. Child Care Health Dev. 2006;32(5):575-83.

87. Scahill L, Aman MG, McDougle CJ, et al. A prospective open trial of guanfacine in children with pervasive developmental disorders. J Child Adolesc Psychopharmacol. 2006;16(5):589-98.

88. Sood R, Coffey BJ. Pharmacotherapeutic challenges in the management of attention-deficit/hyperactivity disorder and chronic tics in a school aged child. J Child Adolesc Psychopharmacol. 2013;23(9):628-31.

89. Speltz ML, Varley CK, Peterson K, Beilke RL. Effects of dextroamphetamine and contingency management on a preschooler with ADHD and oppositional defiant disorder. J Am Acad Child Adolesc Psychiatry. 1988;27(2):175-8.

90. Troost PW, Steenhuis MP, Tuynman-Qua HG, et al. Atomoxetine for attention-deficit/hyperactivity disorder symptoms in children with pervasive developmental disorders: a pilot study. J Child Adolesc Psychopharmacol. 2006;16(5):611-9.

91. Zeiner P, Gjevik E, Weidle B. Response to atomoxetine in boys with high-functioning autism spectrum disorders and attention deficit/hyperactivity disorder. Acta Paediatr. 2011;100(9):1258-61.

92. Ghuman JK, Aman MG, Lecavalier L, et al. Randomized, placebo-controlled, crossover study of methylphenidate for attention-deficit/hyperactivity disorder symptoms in preschoolers with developmental disorders. J Child Adolesc Psychopharmacol. 2009;19(4):329-39.

93. Newcorn JH, Huss M, Connor DF, Hervas A, Werner-Kiechle T, Robertson B. Efficacy of guanfacine extended release in children and adolescents with attention-deficit/hyperactivity disorder and comorbid oppositional defiant disorder. J Dev Behav Pediatr. 2020;41(7):565-70.

94. Cortese S, Panei P, Arcieri R, et al. Safety of methylphenidate and atomoxetine in children with attention-deficit/hyperactivity disorder (ADHD): data from the Italian National ADHD Registry. CNS Drugs. 2015;29(10):865-77.

95. Padilha S, Virtuoso S, Tonin FS, Borba HHL, Pontarolo R. Efficacy and safety of drugs for attention deficit hyperactivity disorder in children and adolescents: a network meta-analysis. Eur Child Adolesc Psychiatry. 2018;27(10):1335-45.

96. Huss M, Dirks B, Gu J, Robertson B, Newcorn JH, Ramos-Quiroga JA. Long-term safety and efficacy of guanfacine extended release in children and adolescents with ADHD. Eur Child Adolesc Psychiatry. 2018;27(10):1283-94.

97. Houghton R, de Vries F, Loss G. Psychostimulants/ atomoxetine and serious cardiovascular events in children with ADHD or autism spectrum disorder. CNS Drugs. 2020;34(1):93-101. 